\title{
Concurrent chemoradiotherapy with $S-1$ in patients with stage III-IV oral squamous cell carcinoma: A retrospective analysis of nodal classification based on the neck node level
}

\author{
RYUJI MURAKAMI ${ }^{*}$, AKIKO SEMBA ${ }^{2 *}$, KENTA KAWAHARA ${ }^{3}$, KEIYA MATSUYAMA ${ }^{2}$, AKIMITSU HIRAKI ${ }^{3}$, \\ MASASHI NAGATA $^{3}$, RYO TOYA ${ }^{2}$, YASUYUKI YAMASHITA ${ }^{4}$, NATSUO OYA ${ }^{2}$ and HIDEKI NAKAYAMA ${ }^{3}$ \\ Departments of ${ }^{1}$ Medical Imaging, ${ }^{2}$ Radiation Oncology, ${ }^{3}$ Oral and Maxillofacial Surgery and \\ ${ }^{4}$ Diagnostic Radiology, Faculty of Life Sciences, Kumamoto University, Kumamoto 862-0976, Japan
}

Received December 1, 2016; Accepted March 13, 2017

DOI: $10.3892 / \mathrm{mco} .2017 .1276$

\begin{abstract}
The aim of the present study was to retrospectively evaluate the treatment outcomes of concurrent chemoradiotherapy (CCRT) with S-1, an oral fluoropyrimidine anticancer agent, for advanced oral squamous cell carcinoma (SCC). The study population consisted of 47 patients with clinical stage III or IV oral SCC, who underwent CCRT with S-1. Pretreatment variables, including patient age, clinical stage, $\mathrm{T}$ classification, midline involvement of the primary tumor and nodal status, were analyzed as predictors of survival. In addition to the $\mathrm{N}$ classification (node-positive, multiple and contralateral), the prognostic impact of the level of nodal involvement was assessed. Nodal involvement was mainly observed at levels Ib and II; involvement at levels Ia and III-V was considered to be anterior and inferior extension, respectively, and was recorded as extensive nodal involvement (ENI). The 3-year overall survival (OS) and progression-free survival (PFS) rates were 37 and $27 \%$, respectively. A finding of ENI was a significant factor for OS [hazard ratio $(\mathrm{HR})=2.16$; $95 \%$ confidence interval (CI): 1.03-4.55; $\mathrm{P}=0.038]$ and $\mathrm{PFS}(\mathrm{HR}=2.65$; 95\% CI: $1.32-5.33$; $\mathrm{P}=0.005$ ); the 3 -year OS and PFS rates in patients with vs. those without ENI were 23 vs. $50 \%$ and 9 vs. $43 \%$, respectively. The other variables were not significant. Therefore, CCRT with S-1 may be an alternative treatment for advanced oral SCC; favorable outcomes are expected in patients without ENI.
\end{abstract}

Correspondence to: Dr Ryuji Murakami, Department of Medical Imaging, Faculty of Life Sciences, Kumamoto University, 4-24-1 Kuhonji, Chuo-ku, Kumamoto 862-0976, Japan

E-mail: murakami@kumamoto-u.ac.jp

*Contributed equally

Key words: cancer staging, chemoradiotherapy, lymph node, oral cancer, prognosis, squamous cell carcinoma

\section{Introduction}

Advanced oral squamous cell carcinoma (SCC) is commonly treated by combined surgery, radiotherapy and chemotherapy; patients with unresectable disease usually undergo concurrent chemoradiotherapy (CCRT) (1-7). Although CCRT is considered to be superior to radiotherapy alone in improving survival, it may not be suitable for elderly patients and/or those with poor performance status (7). S-1 is an oral fluoropyrimidine anticancer agent that combines tegafur [a prodrug of 5-fluorouracil (5-FU)], gimeracil (which inhibits the 5-FU degeneration enzyme dihydropyrimidine dehydrogenase) and oteracil (which reduces the gastrointestinal toxicity of 5-FU). Both tegafur and gimeracil in S-1 have been suggested to have radiosensitizing properties $(8,9)$. The pathological effects of preoperative CCRT with S-1 have been demonstrated in operated patients with advanced oral SCC $(4,5)$. Some case reports suggest the possible efficacy of definitive CCRT with S-1 (6). However, further investigations are required to evaluate the treatment outcomes of CCRT with S-1 for inoperable advanced oral SCC.

The tumor-node-metastasis (TNM) staging system is essential for prognosis prediction, treatment tailoring and the comparison of clinical trials. This system has been updated based on technical advances in diagnostic and treatment methods by close cooperation between the Union for International Cancer Control (UICC) and the American Joint Committee on Cancer (AJCC). Although there are distinct criteria for T-staging at different primary sites, $\mathrm{N}$-staging is the same for all head and neck sites, except the nasopharynx and thyroid gland. The International Consensus Guidelines for the neck node level are also used for tailoring neck dissection and radiotherapy in patients with SCC of the head and neck $(10,11)$. In 2013, the guidelines were further updated to reduce treatment variations among different clinicians and to facilitate the conduct of multi-institutional clinical trials (12). $\mathrm{N}$-staging according to the UICC/AJCC criteria takes into consideration single (N1), multiple- (N2b) and contralateral (N2c) nodes, but not the level of nodal involvement. Recent studies have demonstrated that the level of nodal involvement is a prognostic factor in patients with advanced head and neck $\operatorname{SCC}(13,14)$. 
The aim of the present study was to retrospectively evaluate the treatment outcomes of CCRT with S-1 for advanced oral SCC. Additionally, the prognostic impact of the nodal classification based on the neck node level was assessed.

\section{Patients and methods}

Patient characteristics. Between July, 2004 and October, 2011, 49 patients with advanced oral SCC underwent CCRT with a total radiation dose of 60 or $70 \mathrm{~Gy}$. The patients were not initially treated surgically due to technically and/or medically unresectable disease. Of the 49 patients, 47 (24 men and 23 women; median age, 79 years; age range, $45-91$ years) fulfilled our inclusion criteria of i) histologically verified SCC of the oral cavity, ii) clinical stage III or IV, iii) no distant metastasis and iv) no previous malignancies. Two patients with a previous head and neck malignancy were excluded. The primary tumors were located in the buccal mucosa $(n=4)$, upper gingiva $(n=7)$, lower gingiva $(n=12)$, hard palate $(n=4)$, tongue $(n=16)$ and floor of the mouth $(n=4)$. The clinical stage according to the UICC/AJCC criteria was identified at a conference of oral surgeons, radiologists and radiation oncologists who interpreted the imaging data. The radiological diagnosis of nodal involvement was based on widely accepted morphological criteria $(15,16)$. Of the 47 tumors, one was $\mathrm{T} 1$, 5 were T2, 13 were T3, 15 were T4a and 13 were T4b. Midline involvement of the primary tumor was observed in 24 patients. The clinical node $(\mathrm{cN})$ stage was recorded as $\mathrm{cN} 0$ in 13 , $\mathrm{cN} 1$ in $2, \mathrm{cN} 2 \mathrm{~b}$ in 18 and $\mathrm{cN} 2 \mathrm{c}$ in 14 patients. The pattern of lymph node involvement according to the clinical findings of the primary tumor, i.e., subsite, $\mathrm{T}$ stage and midline involvement, was defined based on the 2013 consensus guidelines (12).

CCRT. A total dose of 60-70 Gy was delivered in 2-Gy fractions using two-threefields. Concurrently, S-1 (TaihoPharmaceutical, Tokyo, Japan) was administered per os $\left(80 \mathrm{mg} / \mathrm{m}^{2} /\right.$ day) for 14 consecutive days followed by a 1-week drug-free period or on the days of irradiation $\left(65 \mathrm{mg} / \mathrm{m}^{2} /\right.$ day $)$ (4-6). The initial radiation fields included the tumor extension and levels I and II, even in cN0 necks; clinically positive as well as equivocal node levels were added in the initial fields. Thereafter, boost irradiation was delivered to the primary tumor and clinically positive nodes. The maximum dose to the spinal cord did not exceed 40 Gy during the two courses of CCRT.

Follow-up evaluation. The patients were followed up to evaluate tumor control. The initial sites of disease progression were classified as local, regional and distant. In patients with failed tumor control salvage surgery, additional radiotherapy and/or additional chemotherapy were considered. Posttreatment survival was measured from the first day of CCRT to the event day or the last day of follow-up. The acute toxicities of CCRT were scored according to the National Cancer Institute Common Terminology Criteria for Adverse Events, version 4.0

Statistical analysis. Pre-treatment variables, including age, clinical stage, T-classification, midline involvement and nodal status, were analyzed as predictors of survival. In addition to the $\mathrm{N}$-classification according to the UICC/AJCC criteria (node-positive, multiple and contralateral), the level of nodal involvement was considered to be a prognostic factor. Overall survival (OS) and progression-free survival (PFS) rates were calculated using the Kaplan-Meier method and compared with the log-rank test. The Cox proportional hazards model was applied to calculate the hazards ratio (HR) and the $95 \%$ confidence interval (CI). All statistical computations were performed using commercial software (IBM SPSS Statistics, version 21, IBM Japan, Tokyo). $\mathrm{P}<0.05$ was considered to indicate statistically significant differences.

\section{Results}

Pattern of lymph node involvement. According to the clinical findings of the primary tumor, the pattern of nodal involvement is presented in Table I. In each status of the primary tumor, the nodal involvement was mainly observed at levels Ib and II; node-positive disease exhibited nodal involvement at these levels. Involvement at levels Ia and III-V was considered, regardless of the laterality, to be anterior and inferior extension, respectively, and was recorded as extensive nodal involvement (ENI).

Accomplishment of CCRT with S-1. All 47 patients underwent radiotherapy as planned; however, the oral administration of S-1 was discontinued in 7 patients who manifested acute toxicity. All 47 patients experienced transient acute mucositis ranging from grade 1 to 3 . The toxicities of grade 3 were mucositis $(n=16)$ and dermatitis $(n=4)$. No grade $\geq 4$ adverse events were encountered.

Outcome and survival analysis. Adjuvant chemotherapy with S-1 was continued for 1-27 months (median, 5 months) in 24 patients without drug-related adverse events. During a median follow-up of 22 months (range, 4-89 months), 19, 8 and 2 patients suffered local, regional and distant progression, respectively. All locoregional progressions $(n=27)$ were observed within the full-dose irradiated regions; 7 patients underwent salvage resection for locoregional progression. The 2 distant progressions were lung metastases. Of the 47 patients in this series, 30 succumbed to primary $(n=23)$ or intercurrent disease $(n=7)$; the 3 -year OS and PFS rates were 37 and $27 \%$, respectively.

Anterior extension to level Ia was a statistically significant prognostic factor for OS $(\mathrm{P}=0.008)$ and $\mathrm{PFS}(\mathrm{P}=0.001)$; however, inferior extension to level III-V was not statistically significant for OS $(\mathrm{P}=0.099)$ and PFS $(\mathrm{P}=0.052)$. Of 22 patients with ENI, including anterior and inferior extension, 10, 8 and 2 suffered local, regional and distant progression, respectively. Consequently, ENI based on the neck node level was a significant prognostic factor for OS $(\mathrm{P}=0.038)$ and $\mathrm{PFS}$ $(\mathrm{P}=0.005)$; the 3 -year OS and PFS rates in patients with vs. those without ENI were 23 vs. $50 \%$ and 9 vs. $43 \%$, respectively (Figs. 1 and 2). Other variables, including the $\mathrm{N}$ classification according to the UICC/AJCC criteria, were not significant (Table II).

\section{Discussion}

Multimodal therapeutic strategies are crucial for the treatment of advanced oral SCC; the 5-year OS rates for operated 
Table I. Clinical nodal level involvement according to the primary tumor characteristics.

Ipsilateral (contralateral) neck node level

\begin{tabular}{|c|c|c|c|c|c|c|c|}
\hline Primary tumor characteristics & $\mathrm{n}$ & Ia & $\mathrm{Ib}$ & II & III & IV & V \\
\hline \multicolumn{8}{|l|}{ Subsite } \\
\hline Buccal mucosa & 4 & - & 3 & $3(1)$ & 3 & 1 & - \\
\hline Upper gingiva & 7 & - & $5(2)$ & $6(3)$ & 1 & 1 & - \\
\hline Lower gingiva & 12 & 4 & $6(2)$ & $3(1)$ & - & - & - \\
\hline Hard palate & 4 & - & 2 & 3 & 1 & - & - \\
\hline Tongue & 16 & 3 & $10(3)$ & $11(2)$ & $7(1)$ & 3 & - \\
\hline Floor of the mouth & 4 & $2(1)$ & $3(2)$ & $4(2)$ & $3(1)$ & 2 & - \\
\hline \multicolumn{8}{|l|}{ T classification } \\
\hline $1-3$ & 19 & 3 & 8 & $12(1)$ & $5(1)$ & 3 & - \\
\hline $4 a$ & 15 & $3(1)$ & $9(6)$ & $7(4)$ & $5(1)$ & 1 & - \\
\hline $4 b$ & 13 & 3 & $12(3)$ & $11(4)$ & 5 & 3 & - \\
\hline \multicolumn{8}{|l|}{ Midline involvement } \\
\hline No & 23 & 1 & $13(3)$ & $14(3)$ & 2 & 3 & - \\
\hline Yes & 24 & $8(1)$ & $16(6)$ & $16(6)$ & $13(2)$ & 4 & - \\
\hline Total & 47 & $9(1)$ & $29(9)$ & $30(9)$ & $15(2)$ & 7 & 0 \\
\hline
\end{tabular}

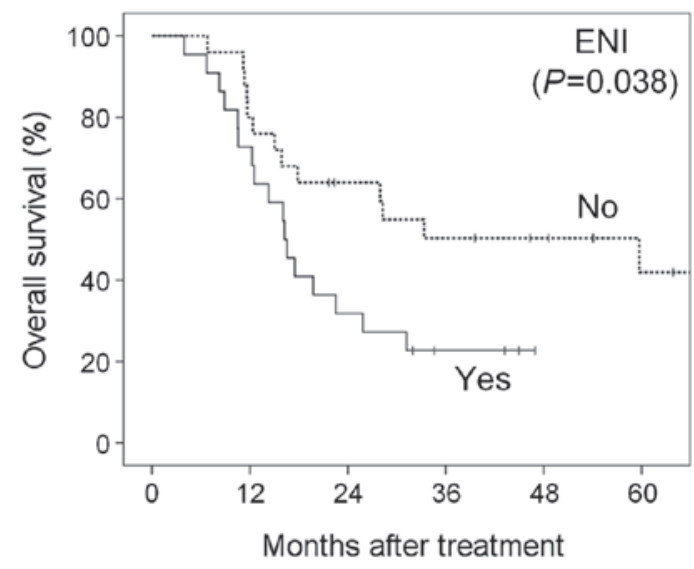

Patients at risk

$\begin{array}{ccccccc}\text { No } & 25 & 20 & 14 & 11 & 9 & 5 \\ \text { Yes } & 22 & 16 & 7 & 3 & 0 & 0\end{array}$

Figure 1. Overall survival curves according to extensive nodal involvement (ENI) based on the neck node level.

cases were reported to be approximately $50 \%$ (17-19). Patients with unresectable disease usually undergo CCRT; the 3-year OS rates of CCRT with cisplatin-based chemotherapy were reported to be $20-30 \%$ (1-3). Although CCRT is superior to radiotherapy alone in improving survival, increasing toxicity must be considered $(20,21)$. To improve treatment outcomes, CCRT with S-1 was administered to patients with advanced oral SCC. In this series, the 3-year OS rate was $37 \%$. Particularly in the 25 patients without ENI, the 3 -year OS and PFS rates were 50 and $43 \%$, respectively. These outcomes were similar to or better than the results achieved with standard

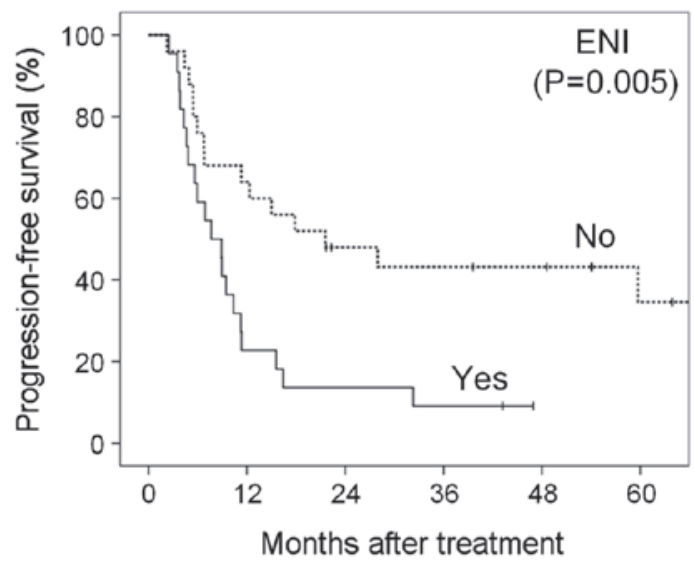

Patients at risk

$\begin{array}{ccccccc}\text { No } & 25 & 16 & 10 & 9 & 8 & 4 \\ \text { Yes } & 22 & 5 & 3 & 2 & 0 & 0\end{array}$

Figure 2. Progression-free survival curves according to extensive nodal involvement (ENI) based on the neck node level.

CCRT using continuous drug infusion, suggesting that CCRT with S-1 may be a feasible alternative treatment.

When nodal involvement at uncommon levels is classified as ENI, the nodal classification based on the neck node level may be a better predictor compared with the UICC/AJCC criteria; the finding of ENI should be taken into account for comparing clinical trials. As the neck node level descends from the submandibular to the supraclavicular region, nodal involvement was considered primarily at levels Ib and II and involvement at levels III-V was defined as inferior extension. The incidence of nodal involvement at level Ia had not been 
Table II. Prognostic factors for overall and progression-free survival.

\begin{tabular}{|c|c|c|c|c|c|c|c|}
\hline \multirow[b]{2}{*}{$\begin{array}{l}\text { Prognostic } \\
\text { factors }\end{array}$} & \multirow[b]{2}{*}{$\mathrm{n}$} & \multicolumn{3}{|c|}{ Overall survival } & \multicolumn{3}{|c|}{ Progression-free survival } \\
\hline & & $\begin{array}{l}\text { Median } \\
\text { (months) }\end{array}$ & $\begin{array}{c}\text { HR } \\
(95 \% \mathrm{CI})\end{array}$ & P-value & $\begin{array}{l}\text { Median } \\
\text { (months) }\end{array}$ & $\begin{array}{c}\text { HR } \\
(95 \% \mathrm{CI})\end{array}$ & P-value \\
\hline Total & 47 & 22.5 & & & 11.3 & & \\
\hline Age, years & & & & 0.586 & & & 0.615 \\
\hline$<79$ & 23 & 22.5 & 1 & & 11.3 & 1 & \\
\hline$\geq 79$ & 24 & 17.5 & $1.22(0.59-2.53)$ & & 9.5 & $1.19(0.61-2.31)$ & \\
\hline Clinical stage & & & & 0.270 & & & 0.292 \\
\hline III & 8 & 59.7 & 1 & & 17.9 & 1 & \\
\hline IV & 39 & 17.5 & $1.80(0.63-5.16)$ & & 9.5 & $1.66(0.64-4.31)$ & \\
\hline $\mathrm{T}$ classification & & & & 0.684 & & & 0.897 \\
\hline $1-3$ & 19 & 17.9 & 1 & & 11.3 & 1 & \\
\hline 4 & 28 & 22.5 & $0.86(0.42-1.78)$ & & 10.4 & $1.05(0.53-2.07)$ & \\
\hline Midline involvement & & & & 0.433 & & & 0.083 \\
\hline No & 23 & 28.3 & 1 & & 17.9 & 1 & \\
\hline Yes & 24 & 16.2 & $1.33(0.65-2.73)$ & & 6.9 & $1.80(0.92-3.53)$ & \\
\hline Node positivity & & & & 0.990 & & & 0.650 \\
\hline No & 13 & 27.9 & 1 & & 17.9 & 1 & \\
\hline Yes & 34 & 19.8 & $1.00(0.45-2.18)$ & & 8.9 & $1.19(0.57-2.48)$ & \\
\hline Multiple nodes & & & & 0.538 & & & 0.538 \\
\hline No & 15 & 28.3 & 1 & & 17.9 & 1 & \\
\hline Yes & 32 & 17.5 & $1.28(0.58-2.80)$ & & 8.9 & $1.25(0.61-2.57)$ & \\
\hline Contralateral node & & & & 0.330 & & & 0.306 \\
\hline No & 33 & 27.9 & 1 & & 11.3 & 1 & \\
\hline Yes & 14 & 17.5 & $1.46(0.68-3.12)$ & & 7.7 & $1.44(0.71-2.90)$ & \\
\hline Level Ia involvement & & & & 0.008 & & & 0.001 \\
\hline No & 38 & 28.3 & 1 & & 12.3 & 1 & \\
\hline Yes & 9 & 16.5 & $2.83(1.27-6.33)$ & & 4.8 & $3.56(1.60-7.94)$ & \\
\hline Level III-V involvement & & & & 0.099 & & & 0.052 \\
\hline No & 30 & 28.3 & 1 & & 15.0 & 1 & \\
\hline Yes & 17 & 14.3 & $1.85(0.88-3.88)$ & & 8.9 & $1.95(0.98-3.87)$ & \\
\hline $\mathrm{ENI}^{\mathrm{a}}$ & & & & 0.038 & & & 0.005 \\
\hline No & 25 & 59.7 & 1 & & 21.6 & 1 & \\
\hline Yes & 22 & 16.2 & $2.16(1.03-4.55)$ & & 7.7 & $2.65(1.32-5.33)$ & \\
\hline
\end{tabular}

${ }^{a}$ Nodal involvement at uncommon levels, i.e., anterior extension to level Ia and/or inferior extension to levels III-V. CI, confidence interval; ENI, extensive nodal involvement; HR, hazards ratio.

elucidated, as the majority of previous studies on the distribution of nodal involvement did not subdivide level I into Ia and Ib. Otherwise, level I was considered to be only submandibular nodes (level Ib) (22). Woolgar reviewed 439 patients who underwent neck dissection for oral or oropharyngeal cancer and reported no cases with isolated involvement at level Ia (23). Lymphatic drainage from organs follows several pathways that include main collection and alternative routes (11). These findings support the findings of the present study and level Ia is considered to be an uncommon site representing an alternative route due to the involvement at more common levels.
This retrospective study had certain limitations. Pathological confirmation of the nodal status could not be obtained, as our patients underwent CCRT after clinical staging based on radiological examinations. However, up-to-date radiological examinations may yield a correct determination of nodal involvement $(15,16)$. This study included several elderly patients (median age, 79 years). Intercurrent diseases affect the treatment outcomes and our retrospective study may have included patients treated with palliative intent. Despite these limitations, CCRT with $\mathrm{S}-1$ is feasible and effective in patients with advanced oral SCC. Our study population consisted of inoperable patients with 
stage III or IV oral SCC. Therefore, node-negative patients had unresectable T3 or T4 tumors, whereas T1 and T2 tumors had nodal involvement. The selection bias may provide no correlation between the UICC/AJCC criteria and survival. Although our data demonstrated that a finding of ENI, i.e., nodal involvement at uncommon levels, is of prognostic relevance, the criteria of ENI should be assessed for each primary site of head and neck SCCs with different lymphatic pathways. Prospective studies are required to validate the treatment outcomes of CCRT with S-1 and the prognostic impact of the nodal classification based on the neck node level.

\section{Acknowledgements}

The present study was supported by the Japan Society for the Promotion of Science KAKENHI (grant no. 25461918).

\section{References}

1. Gore SM, Crombie AK, Batstone MD and Clark JR: Concurrent chemoradiotherapy compared with surgery and adjuvant radiotherapy for oral cavity squamous cell carcinoma. Head Neck 37: $518-523,2015$.

2. Crombie AK, Farah C, Tripcony L, Dickie G and Batstone MD: Primary chemoradiotherapy for oral cavity squamous cell carcinoma. Oral Oncol 48: 1014-1018, 2012.

3. Lin CY, Wang HM, Kang CJ, Lee LY, Huang SF, Fan KH, Chen EY, Chen IH, Liao CT and Chang JT: Primary tumor site as a predictor of treatment outcome for definitive radiotherapy of advanced-stage oral cavity cancers. Int J Radiat Oncol Biol Phys 78: 1011-1019, 2010.

4. Nomura T, Murakami R, Toya R, Teshima K, Nakahara A, Hirai T, Hiraki A, Nakayama H, Yoshitake Y, Ota K, et al: Phase II study of preoperative concurrent chemoradiation therapy with $\mathrm{S}-1$ in patients with T4 oral squamous cell carcinoma. Int J Radiat Oncol Biol Phys 76: 1347-1352, 2010.

5. Harada H, Omura K, Tomioka H, Nakayama H, Hiraki A, Shinohara M, Yoshihama Y and Shintani S: Multicenter phase II trial of preoperative chemoradiotherapy with S-1 for locally advanced oral squamous cell carcinoma. Cancer Chemother Pharmacol 71: 1059-1064, 2013.

6. Yoshizawa K, Nozaki S, Yoshida K, Kawashiri S, Kato K, Nakagawa $\mathrm{K}$ and Yamamoto E: Two elderly patients with advanced maxillary gingival carcinoma with complete response to concurrent radiotherapy and S-1 chemotherapy. Asian J Oral Maxillofacial Surg 22: 94-98, 2010.

7. Pignon JP, le Maître A, Maillard E and Bourhis J; MACH-NC Collaborative Group: Meta-analysis of chemotherapy in head and neck cancer (MACH-NC): An update on 93 randomised trials and 17,346 patients. Radiother Oncol 92: 4-14, 2009.

8. Harada K, Kawaguchi S, Supriatno, Onoue T, Yoshida H and Sato M: Combined effects of the oral fluoropyrimidine anticancer agent, S-1 and radiation on human oral cancer cells. Oral Oncol 40: 713-719, 2004

9. Nakagawa T, Otsuki N, Masai Y, Sasaki R, Tsukuda M and Nibu K: Additive effects of oral fluoropyrimidine derivative S-1 and radiation on human hypopharyngeal cancer xenografts. Acta Otolaryngol 128: 936-940, 2008

10. Gregoire V, Levendag P, Ang KK, Bernier J, Braaksma M, Budach V, Chao C, Coche E, Cooper JS, Cosnard G, et al: CT-based delineation of lymph node levels and related CTVs in the node-negative neck: DAHANCA, EORTC, GORTEC, NCIC,RTOG consensus guidelines. Radiother Oncol 69: 227-236, 2003
11. Vorwerk H and Hess CF: Guidelines for delineation of lymphatic clinical target volumes for high conformal radiotherapy: Head and neck region. Radiat Oncol 6: 97, 2011.

12. Gregoire V, Ang K, Budach W, Grau C, Hamoir M, Langendijk JA, Lee A, Le QT, Maingon P, Nutting C, et al: Delineation of the neck node levels for head and neck tumors: A 2013 update. DAHANCA, EORTC, HKNPCSG, NCIC CTG, NCRI, RTOG, TROG consensus guidelines. Radiother Oncol 110: 172-181, 2014.

13. Xing Y, Zhang J, Lin H, Gold KA, Sturgis EM, Garden AS, Lee JJ and William WN Jr: Relation between the level of lymph node metastasis and survival in locally advanced head and neck squamous cell carcinoma. Cancer 122: 534-545, 2016.

14. Murakami R, Nakayama H, Semba A, Hiraki A, Nagata M, Kawahara K, Shiraishi S, Hirai T, Uozumi H and Yamashita Y: Prognostic impact of the level of nodal involvement: Retrospective analysis of patients with advanced oral squamous cell carcinoma. Br J Oral Maxillofac Surg 55: 50-55, 2017.

15. Ng SH, Yen TC, Liao CT, Chang JT, Chan SC, Ko SF, Wang HM and Wong HF: 18F-FDG PET and CT/MRI in oral cavity squamous cell carcinoma: A prospective study of 124 patients with histologic correlation. J Nucl Med 46: 1136-1143, 2005.

16. Murakami R, Uozumi H, Hirai T, Nishimura R, Shiraishi S, Ota K, Murakami D, Tomiguchi S, Oya N, Katsuragawa S and Yamashita Y: Impact of FDG-PET/CT imaging on nodal staging for head-and-neck squamous cell carcinoma. Int J Radiat Oncol Biol Phys 68: 377-382, 2007.

17. Amit M, Yen TC, Liao CT, Chaturvedi P, Agarwal JP, Kowalski LP, Ebrahimi A, Clark JR, Kreppel M, Zöller J, et al: Improvement in survival of patients with oral cavity squamous cell carcinoma: An international collaborative study. Cancer 119: 4242-4248, 2013.

18. Kreppel M, Drebber U, Rothamel D, Eich HT, Kubler A, Scheer M and Zöller JE: Prognostic impact of different TNM-based stage groupings for oral squamous cell carcinoma. Head Neck 33: 1467-1475, 2011.

19. Kessler P, Grabenbauer G, Leher A, Bloch-Birkholz A, Vairaktaris E and Neukam FW: Neoadjuvant and adjuvant therapy in patients with oral squamous cell carcinoma Long-term survival in a prospective, non-randomized study. Br J Oral Maxillofac Surg 46: 1-5, 2008.

20. Browman GP, Hodson DI, Mackenzie RJ, Bestic N and Zuraw L; Cancer Care Ontario Practice Guideline Initiative Head and Neck Cancer Disease Site Group: Choosing a concomitant chemotherapy and radiotherapy regimen for squamous cell head and neck cancer: A systematic review of the published literature with subgroup analysis. Head Neck 23: 579-589, 2001.

21. Adelstein DJ, Li Y, Adams GL, Wagner H Jr, Kish JA, Ensley JF, Schuller DE and Forastiere AA: An intergroup phase III comparison of standard radiation therapy and two schedules of concurrent chemoradiotherapy in patients with unresectable squamous cell head and neck cancer. J Clin Oncol 21: 92-98, 2003.

22. Jones AS, Roland NJ, Field JK and Phillips DE: The level of cervical lymph node metastases: Their prognostic relevance and relationship with head and neck squamous carcinoma primary sites. Clin Otolaryngol Allied Sci 19: 63-69, 1994.

23. Woolgar JA: The topography of cervical lymph node metastases revisited: The histological findings in 526 sides of neck dissection from 439 previously untreated patients. Int J Oral Maxillofac Surg 36: 219-225, 2007. 